\title{
Etiopatogenia da febre reumática ${ }^{(*)}$
}

\section{Etiopathogenesis of the rheumatic fever}

\author{
Acir Rachid ${ }^{(1)}$
}

\section{RESUMO}

O autor afirma que, embora haja plena aceitação da responsabilidade do estreptococo beta hemolítico na etiologia da febre reumática (FR), persistem dúvidas se há concomitante uma afecção viral. Revisa as estruturas do estreptococo e chama atenção para o fato de que cada surto da doença é produzido por um sorotipo diferente do estreptococo. Resume os mecanismos patogênicos em três modos diferentes: a) ação lenta das bactérias; b) ação tóxica dos produtos, como a exotoxina; c) fenômenos de hipersensibilidade. Enfatiza a descoberta do antígeno de células B denominado D8/17.

Palavras-chave: febre reumática (FR), estreptococo beta hemolítico, antiestreptolisina O, proteína M, HLA-DR7, D/8 17, cardite reumática, coréia reumática.

No estudo etiopatogênico da febre reumática (FR) está estabelecida firmemente, há muitos anos, a responsabilidade do Estreptococo beta-hemolítico do grupo A de Lancefield, embora persistam dúvidas, como veremos adiante, de que seja causador isoladamente, ou com algum co-participante.

Sabe-se também que deverá, previamente, existir uma orofaringite, clínica ou assintomática, com cura aparente. Após um intervalo livre de 18 a 21 dias, verificar-se-á o aparecimento de uma série de sinais e sintomas que constituirá a febre reumática.

Aceita-se plenamente que o indivíduo atingido deverá ter uma suscetibilidade determinada geneticamente, o que explicará por que somente uma mínima porção $(1 \%$ a $2 \%$ dos portadores da faringite estreptocócica desenvolverá a FR.

\begin{abstract}
Although there is a consensus about the responsibility of betahemolytic streptococcus in the rheumatic fever (RF) etiology, in this article the author claims that persist doubts about a possible concomitant viral condition. This paper also reviews the streptococcus structures and stresses the fact that each outbreak of the disease is produced by a different streptococcus serotype. Concerning the pathogenesis, the author discusses three different mechanisms: a) slow bacterial action, b) the action produced by toxins and c) hypersensitivity reactions. Finally, the author also emphasizes the recent discovery of a $B$ cell antigen called $D$ 8/17.
\end{abstract}

Keywords: rheumatic fever (RF), beta-hemolytic streptococcus, antistreptolysin O, M protein, HLA-DR7, D/8 17, rheumatic carditis, rheumatic chorea.

Além da possibilidade da identificação prévia da amigdalite, evidências indiretas da responsabilidade do estreptococo têm sido ressaltadas:

1. Surtos esporádicos atuais de FR estão intimamente ligados a epidemias de faringite estreptocócica ou da febre escarlatina.

2. O tratamento correto da faringite previne o aparecimento ou a recorrência da FR.

3. Os estudos dos anticorpos antiestreptocócicos, se determinados na sua totalidade (antiestreptolisina $\mathrm{O}$, antihialuronidase, antiestreptoquinase e antidesoxirribonuclease D), mostrar-se-ão sempre positivos e em títulos elevados nessa fase aguda ${ }^{(1)}$.

Mesmo nos locais onde a febre reumática se tornou rara, a faringite pelo estreptococo continua a existir, mas por

\footnotetext{
* Departamento de Clínica Médica da Universidade Federal do Paraná (UFPR). Recebido em 11/03/2002. Aprovado, após revisão em 10/12/2002.

1. Professor Titular e Professor Sênior do Departamento de Clínica Médica da UFPR, Livre Docente em Reumatologia do DCM, UFPR e Chefe do Setor IV do Departamento de Clínica Médica da UFPR. 
cepas de baixa virulência ou por tipos não reumatogênicos. As piodermites causadas por estreptococos pertencentes a outros sorotipos não são reumatogênicas, mas causam glomerulonefrite difusa aguda, o que dá crédito que a divisão entre reumatogênicos e nefritogênicos é procedente e real.

Contudo, esse conceito de que só a faringite produz FR ficou um tanto abalado com o estudo de Carapetis et al. ${ }^{(2)}$, que avaliaram a população aborígene da Austrália, onde não existe faringite estreptocócica e a piodermite estreptocócica é endêmica, atingindo mais de $70 \%$ das crianças em algumas comunidades, sendo o índice ainda mais elevado se houver concomitantemente a escabiose. Nesse grupo populacional existe a FR que então é considerada proveniente da infecção de pele por estreptococos reumatogênicos. Metade dos episódios de FR não foi precedida de faringite sintomática e 38\% desses pacientes com FR tinham recente infecção de pele, e uma das duas cepas mais comuns era de um sorotipo piodérmico.

Um dos maiores problemas do questionamento etiopatológico da FR é ela aparecer ou deixar seqüelas sem evidenciar a faringite estreptocócica. Questionou-se a responsabilidade única do estreptococo na produção das lesões valvares e demonstrou-se que infecções virais também poderiam produzi-las.

Desde 1960 sabe-se que viroses pelo Coxsackie B são responsáveis por certa proporção de doença cardíaca adquirida, incluindo pericardite, miocardite e a própria endocardite. Casos clássicos de regurgitação mitral e aórtica têm sido documentados, e alguns até apresentam recorrências do ataque cardíaco. Esses estudos tornam-se interessantes na FR, principalmente porque casos considerados como de etiologia estreptocócica e com tratamento preventivo adequado apresentam recorrências. No estudo de Zaher et al..$^{(3)}$, cinco pacientes ilustraram essa evidência, demonstrando que a virose ocorreu antes da infecção estreptocócica. Outros estudos citados nesse trabalho também mostram esta correlação. Os autores aconselham que, antes de se responsabilizar somente o estreptococo nos casos em que a pesquisa laboratorial foi negativa para o estreptococo, se realizem exames para identificar o vírus Coxsackie B.

A estrutura do estreptococo está bem esclarecida. O papel da cápsula, formada pelo hialuronato, é responsável pela reação imunológica cruzada com complexos do tipo proteínas e polissacarídeos, encontrados nos tecidos humanos e que são importantes determinantes das manifestações articulares, cardíacas e do sistema nervoso da doença.
A parede celular em que se encontram as proteínas $\mathrm{M}, \mathrm{T}$ e $\mathrm{R}$ determina a alta antigenicidade, que leva à formação dos anticorpos. A proteína M é a mais importante, está adequadamente estudada e é responsável pela caracterização de cerca de 80 tipos diferentes de estreptococos, diferenciados em reumatogênicos e nefritogênicos. Cada surto de FR é determinado por um tipo, havendo não só uma variação geográfica importante, mas também uma proteção imunológica, de tal maneira que se houver uma recorrência da FR, será por um tipo diferente.

A camada média, rica em carboidratos que possuem propriedades antigênicas, permite classificar os estreptococos em grupos, que variam do A até O. A camada interna, que é formada por mucopeptídeos, que são responsáveis pela forma do estreptococo, contém glicose, o que revela a contaminação do produto por resíduos da membrana.

Amostras bacterianas desprovidas de parede, os protoplastos e as chamadas formas em L parecem ter eventual significação na gênese da doença e talvez expliquem a falha do tratamento profilático, que ocorre por vezes ${ }^{(1)}$.

Os produtos extracelulares bem individualizados e que possuem funções específicas são: estreptolisina $O$, estreptolisina S, hialuronidase, desoxiribonuclease A, B, C e D, toxina eritrogênica e proteinase estreptocina A.

É importante acentuar que a antigenicidade é própria da estreptolisina $\mathrm{O}$, já que a $\mathrm{S}$ não tem esta propriedade. Mesmo que as infecções de pele, estreptocócicas, produzam a estreptolisina $\mathrm{O}$, esta é inativada pelo colesterol e por outros lipídios que, se agregando à sua molécula, retiram o seu poder antigênico. Sempre que o resultado do teste para a ASO for negativo, deve-se repeti-lo mais 2 a 3 vezes a curto prazo.

Diversos livros e textos trazem elucidações sobre esses aspectos da $\mathrm{FR}^{(1,4)}$. Os mecanismos patogênicos têm sido centrados em três modos diferentes de ação:

1. Por ação direta das bactérias, discutindo-se a necessidade da presença de microorganismos vivos nos tecidos agredidos pela FR. Aceita-se que embora tenha sido provada a presença de alguns estreptococos em tecidos afetados, estes são, na maioria das vezes, representados por estruturas inframicroscópicas bem identificadas pela microscopia eletrônica e comparáveis às formas $\mathrm{L}$ dos vírus. Contudo, ainda não se determinou o verdadeiro papel dessas estruturas.

2. Por ação tóxica dos produtos deletérios depositados nos tecidos afetados, a estreptolisisna $\mathrm{O}$, a principal exotoxina estreptocócica, é reconhecida como um fator tóxico 
importante, provado pela injeção EV em pessoas normais, que passarão a apresentar alterações eletrocardiográficas específicas. Apesar disso, não é acreditável ter um papel relevante na gênese da FR.

3. Fenômenos de hipersensibilidade e auto-imunidade.

Para a afirmação dessa última teoria, é preciso reconhecer que os indivíduos afetados teriam uma sensibilidade especial, determinada geneticamente, e que há necessidade de se conhecer o mimetismo molecular e também que os estudos da imunidade celular e humoral nos permitam entender a complexidade desses fenômenos.

O fenômeno do mimetismo idiotípico refere-se à habilidade de alguns anticorpos antiidiotípicos reproduzirem algumas das propriedades imunoquímicas do antígeno. Esses anticorpos antiidiotípicos são produzidos durante a resposta imune normal.

O mimetismo molecular entre a miosina e a proteína $M$ parece ser um importante fator na reação cruzada humoral e na imunidade de células T contra o estreptococo do grupo A e o coração. Portanto, anticorpos ligados às células $\mathrm{T}$ (interação entre linfócitos T e B) estão intimamente envolvidos na reação cruzada imunológica com o coração na FR.

Esses estudos da reação cruzada ainda estão em uma etapa preliminar. Espera-se que em breve estejam identificados e esclarecidos quais os tipos de células $\mathrm{T}$ responsáveis. Estudos mais profundos sobre a proteína $\mathrm{M}$ e outros antígenos estreptocócicos envolvidos no mimetismo molecular devem explicar melhor o processo da auto-imunidade, bem como as seqüelas infecciosas ${ }^{(4)}$.

Está comprovada a existência de complexos imunes nos paciente com febre reumática, mas não se provou uma deposição deletéria em algum órgão ou ativação do complemento do soro. Todavia, a sinovite, que, embora leve, pode existir na FR, seria conseqüência da geração de complexos imunes e do consumo de complemento no espaço articular.

No tocante à interpretação do processo imunológico no coração, afirma-se que o corpo de Aschoff é patognomônico, mas pode não representar atividade da doença. $\mathrm{O}$ coração está fortemente infiltrado de células mononucleares com distribuição focal, dentro do miocárdio. As valvas são infiltradas na fase aguda e podem ficar com lesões residuais focais, fibróticas, havendo posteriormente calcificações agregadas à fibrose. A infiltração é predominantemente de linfócitos CD3/CD4.

Para melhor esclarecimento do complexo mecanismo fisiopatológico que ocorre na febre reumática, abordaremos separadamente a importância da genética, da imunidade celular e da imunidade humoral.

\section{A GENÉTICA DA FEBRE REUMÁTICA}

$\mathrm{O}$ fato de que somente uma minoria dos atingidos por faringite estreptocócica desenvolve a FR levou à suspeita e, posteriormente, à prova de que alguns sorotipos são reumatogênicos e outros não. Conhecidos cerca de 50 tipos diferentes de cepas tidas como reumatogênicas, ao contrário de poucas, mas diferentes, nefritogênicas. Além disso, havia a suposição de que para a transformação da infecção em uma doença, a FR, exigiria uma especial condição ou a presença de algum fator que tornasse possível tal acontecimento. E ainda os indivíduos que tivessem a infecção pela primeira vez ficariam suscetíveis a novas reinfecções, mas esse novo surto de FR seria causado por um outro tipo de estreptococo como agente infectante.

Também registrada uma agregação familiar nítida nos gêmeos monozigóticos e completamente diversa dos gêmeos dizigóticos ${ }^{(5)}$.

A comunidade científica voltou-se para o estudo do sistema HLA e foi mostrada uma relação razoavelmente aumentada entre a incidência da FR e os HLA-DR1, DR2, DR4, DR7 e DRW53 ${ }^{(6)}$. Um achado curioso, mas constante em vários estudos, é que a ligação com determinados alelos é verificada somente em certas áreas geográficas e não reproduzível em outras. Assim, como exemplo citamos o trabalho de Visentaimer et al..$^{(7)}$, feito no Paraná, em que foram estudados 13 antígenos HLA-DR e 3 antígenos HLADQ; os resultados confirmaram uma associação positiva com o HLA-DR7 (46,7\% versus $25,7 \%)$, mas não com o DR53 $(54,3 \%$ versus $44,5 \%)$. O risco relativo à fração etiológica foi de $2,4 \%$ e $0,27 \%$, respectivamente. Parece, pois, que nessa região geográfica brasileira existiria uma predisposição maior para a $\mathrm{FR}^{(8)}$.

Outros estudos ${ }^{(9,10)}$ mostraram que DR4 foi relatado ser mais comum na cardiopatia reumática do que em controles e que com relação ao DR6 foi identificado exatamente o oposto.

Várias pesquisas sobre a histocompatibilidade e a FR estão resumidas no trabalho de Olivier ${ }^{(11)}$, em que se salienta o achado de Ayoub de uma freqüência aumentada dos HLA-DR4 em pacientes brancos e HLA-DR2 nos negros. Também são enumerados os achados seguintes: DR7 e DRw6 na África do Sul; DR7 e Dw53 no Brasil; Dqw2 na Índia; HLA-B 17, HLA B21 e HLA Cw4 na Rússia. 
Em 1979, Patarroyo ${ }^{(12)}$ encontrou um marcador nas células B dos pacientes com FR e cardite que denominou 833, mas posteriormente outros investigadores não puderam validar sua importância ${ }^{(8)}$. Mais adiante, Zabriskie ${ }^{(13)}$ demonstrou associação com aloantígeno de células $\mathrm{B}$, reconhecido pelo anticorpo monoclonal D8/17, em pacientes com FR. O assunto continua em investigação e com possibilidades de aceitação pela comunidade científica. Essas moléculas D8/17 associadas as HLA-DR são geneticamente inatas e também encontradas com maior freqüência nas mães dos pacientes com FR, em comparação com os grupos-controles.

Dessa forma, originou-se outro estudo, que está sendo conduzido com a orientação do Dr. Romeo Rodriguez, diretor do Hospital Infantil do México. São observadas cerca de 3.000 crianças não afetadas, na área da cidade do México, onde existe uma alta incidência de FR, e essas crianças estão sendo testadas quanto à presença do marcador D8/17, das quais 124 apresentavam valores 1 SD acima do normal. Após 1 ano ainda não foi notificado nenhum caso de FR nas crianças testadas, mas há necessidade de maior número de crianças e maior tempo de evolução ${ }^{(13,14)}$.

\section{A IMUNIDADE CELULAR NA FEBRE REUMÁTICA}

Há muitos anos procura-se estabelecer uma possível hipersensibilidade ao estreptococo, e também aos seus produtos, nos pacientes com FR, como acontece na sensibilidade à tuberculina nos pacientes portadores de tuberculose.

Em animais, provou-se a necessidade de inúmeras inoculações de produtos estreptocócicos, produzindo um prérequisito primário para formar em seqüência as lesões patológicas parecidas com a FR em humanos.

Essas reações foram mais intensas e freqüentes nos indivíduos reumáticos do que nos controles não reumáticos, e muito mais intensas se usados os produtos de cepas de estreptococos hemolíticos do que dos não hemolíticos. Também houve diferenças se usados estreptococos autógenos. Isso explica bem por que em humanos há necessidade de várias infecções prévias para desenvolver a FR e por que ela é rara antes dos 3 anos de idade.

Algumas observações são conclusivas para eventos importantes:

1. Existiria uma reatividade celular acentuada em paciente com FR para membranas celulares do estreptococo do grupo A com reação antigênica cruzada com o sar- colema cardíaco. Isso persistiria por até 5 anos após o ataque inicial da infecção estreptocócica. Depois de 5 anos, os indivíduos responderiam de modo normal a uma nova infecção. Se indivíduos normais são infectados inicialmente por uma infecção estreptocócica não complicada, reagirão aos antígenos da membrana de modo normal.

2. A especificidade da reatividade celular ao grupo A do estreptococo está bem provada porque as membranas dos grupos C e D dão respostas, quer em pessoas reumáticas como não reumáticas, de modo diferente e consideradas normais.

3. Os complexos antígenos-anticorpos não parecem representar um papel predominante na resposta celular aos antígenos estreptocócicos. A natureza do antígeno responsável não está reconhecida até recentemente. Os estudos excluem a proteína $M$ dessa responsabilidade. Há sugestão de que a porção lipoprotéica da membrana celular represente um papel importante nesta reação.

Provadamente se encontram linfócitos e macrófagos onde existe dano patológico nos pacientes com FR. Na fase aguda da doença, a relação de CD4+/CD8+ é igual a 4:1, mas na cronificação os números aproximam-se. Um achado importante é que os fibroblastos like-macrófagos expressam antígenos DR4 que podem funcionar como apresentadores de linfócitos CD4+.

A reatividade celular aumentada na FR pode durar até meses depois do surto ou persistir por 2 anos. Essa hiperatividade é específica somente para as cepas do estreptococo que produzem a FR, sugerindo fortemente uma resposta humoral e celular anormal.

Há também o registro de que valvas lesadas pela FR, quando removidas, fazem cair aceleradamente o nível de anticorpos ao carboidrato estreptocócico, até atingir a normalidade. Essa observação contribui para reconhecer que o mimetismo molecular é de fundamental importância para a patogênese da cardiopatia reumática na sua forma crônica.

Cunninghan et al. ${ }^{(15)}$ demonstraram que existem vários marcadores da ativação celular na FR, além de linfócitos CD4, interleucinas 1 e 2 , receptores positivos de células $\mathrm{T}$, neopterin, receptores do fator de necrose tumoral alfa, inibição da migração de leucócitos, citoxicidade de células NK, citoxicidade de células mononucleares e produção de radicais de oxigênio livre. 


\section{A IMUNIDADE HUMORAL NA FEBRE REUMÁTICA}

O conceito moderno de FR é que seja resultante de uma resposta imune anormal, por parte do hospedeiro, a uma infecção por determinados tipos do estreptococo beta-hemolítico do grupo A de Lancefield.

O passo seguinte foi a demonstração de que o antígeno estaria presente quando a infecção fosse por determinados tipos de estreptococo e que poderia apresentar reação cruzada com tecido cardíaco e/ou sistema nervoso.

Os antígenos produzidos pelas toxinas extracelulares dos estreptococos estimulam grande número de células $\mathrm{T}$, levando a uma interação dos receptores destas células $\mathrm{T}$ do tipo específico V-beta com moléculas da classe II MHC.

Essas células $\mathrm{T}$ ativadas elaborariam fator de necrose tumoral, gama-interferon e algumas interleucinas, contribuindo sobremaneira para o dano patológico. Contudo, nenhum dado concernente ao papel do superantígeno na FR tem sido provado.

A favor dessa teoria tem sido documentada a presença de anticorpos no soro dos pacientes com FR, em uma proporção de $30 \%$ a $85 \%$. Contudo, esses mesmos anticorpos podem ser detectados em indivíduos sadios, principalmente nos que tiveram infecções estreptocócicas que não progrediram para FR. Essas pessoas, entretanto, têm títulos em níveis mais baixos, que podem desaparecer a curto prazo.

$\mathrm{O}$ soro dos pacientes com FR pode ter um padrão de imunofluorescência que cora mais intensamente na região do sarcolema, mas inexplicavelmente não se relaciona obrigatoriamente com a presença de cardite concomitante. Somente a intensidade desse tingimento é mais acentuada nos reumáticos do que naqueles com uma simples estreptococia ${ }^{(2)}$.

Nos pacientes com FR, esses anticorpos reativos ao coração podem desaparecer em um período de 3 anos, desde que não apareçam novos surtos de FR. Com relação à ASO, a sua grande elevação (1.250 U a $2.500 \mathrm{U}$ ) e persistência nem sempre se correlacionam com o estado clínico ou com o desenvolvimento da FR. Também é registrado que a recorrência da FR após 5 anos do surto inicial se

\section{REFERÊNCIAS}

1. Decourt LV: Doenças reumáticas. São Paulo: Saraiva, 9, 1972.

2. Carapatis SJR, Wolff DR, Curris JR: Acute Rheumatic Fever and rheumatic heart disease in the top end of Australian northern territory. Med J Austral 164: 146-9, 1966.

3. Zaher SR, Kassam AS, Hughes JJ: Cocksackie virus infection in Rheumatic Fever. Indian J Pediatr 60: 289-98, 1993. torna muito menos provável, independentemente da maior ou menor elevação dos anticorpos anti-estreptocócicos. Há, contudo, registro de recorrências até 11 anos depois do último surto ${ }^{(4)}$.

Não se despreza a opinião de que esses anticorpos podem ser produzidos por todas as infecções do estreptococo do grupo A, mas seriam mais intensamente com os tipos que produzem a FR, isto é, com os reumatogênicos.

Os pacientes com FR também possuem anticorpos antimiosina e tropomiosina em níveis elevados, se comparados aos encontrados em pacientes só com faringite estreptocócica e que não evoluíram com FR. Possuem reação cruzada com a proteína $\mathrm{M}$ e há suspeita de que esta proteína seja o estímulo antigênico necessário à produção dos anticorpos contra miosina.

Os pacientes com coréia reumática possuem anticorpos contra o núcleo caudado. Um achado até agora insolúvel é a presença de anticorpos reativos ao coração em pessoas normais e sem provas de recente infecção estreptocócica. Também anticorpos análogos têm sido vistos em pessoas submetidas à cirurgia cardíaca.

A vasculite por complexos imunes, que pode ser provocada pela FR, processa-se pela deposição de complexos imunes na parede dos vasos e pela penetração dos anticorpos, causando o dano vascular. Também se acredita que nos nódulos de Aschoff e na sua circunvizinhança se encontrem deposições de imunoglobulinas e complemento.

Em um estudo feito no Laboratório de Imunopatologia da Universidade Federal do Paraná-UFPR cujo objetivo foi determinar se a proteína do complemento BF, C2, C4 (C4A e C4B), pertencentes a classe III do MHC, estava presente nos portadores de cardiopatia reumática e em 65 controles, todos pacientes do Hospital das Clínicas da UFPR, mostrou-se uma freqüência aumentada do alelo $\mathrm{C} 4 \mathrm{~A} * 6$ (raro) e uma diminuição do C4A*3. Concluíram os autores pela necessidade de mais estudos, de estabelecer o significado deste achado, e sugerem também o estudo nos casos de FR sem cardite $^{(16)}$.

4. Gibopsky A, Zabrieskie JB: Rheumatic Fever: etiology, diagnosis and treatment. In: Arthristis and allied conditions. Baltimore: Williams \& Wilkins, 1581-7, 1992.

5. Taranta A, Torosdag S, Mitrakos JD, Jegier W, Lichid I: Rheumatic Fever in monozygotic and dizygotic twins. Circulation: 20: 77882, 1959

6. Narula, J, et al: Rheumatic Fever. Inst. of pathology. Washington D.C. 2306-6000, 1999. 
7. Visentainer JEL, Pereira FC, Dalalis MO, Donadio PR, Moliterno RA: Association pf HLA DR7 with Rheumatic Fever in the Brazilian population. J Rheumat 27: 1518-20, 2000.

8. Guilherme L, Weidebach W, Kiss MH, Snitecwsky R, Kalil J: Association of HumanLeukocyt class II antigens with Rheumatic Fever in rheumatic Heart Disease in a Brazilian population. Circulation 83: 1995-8, 1991.

9. Kemeny E, Grieve T, Marcus R, Sareli P, Zabriskie JB: Identification of mononuclear cells and $\mathrm{T}$ cells sub-sets in rheumatic valvulitis. Clin Imunol Immunopath 52: 225-37, 1989.

10. Anastasiou Nana MC, Anderson JL, Carguist JR: HLA-DR typing and lymphocyte sub-set evalution in rheumatic heart disease. A search for immune response factors. Am Heart J 5: 993-8, 1986.

11. Olivier C: Lerhumatisme articulaire aigu chez l'enfant in 1997. Pathol Biologie 46: 802-12, 1998.

12. Patarroyo ME, Winchester R, Veprano A: Association of B-cell alloantigen with susceptibility of Rheumatic Fever. Nature 278: 173-4, 1979.
13. Zabrieskie E, Khanna AK, Buskirk DR, Willians RC: Presence of a non-HLA cell antigen in Rheumatic Fever patients and their families as defined by a monoclonal antibody. J Clin Investig 83: 1710-6, 1989.

14. Zabrieskie JB, Rodriguez RS: Studies of a B-cell called D8/17 and its relationship to Rheumatic Fever, and disease susceptibility. In Narula, et al: Rheumatic Fever. Instit. of Pathology. Washington D.C. 463-71, 2030-6000, 1999.

15. Cunninghan MW, Swalick RA: Polispecifity of anti-streptococcal murine monoclonal antibodies and their implications in autoimmunity. J Exp Med 165: 998-1005, 1996.

16. Messias I, Cavalcanti R, Radominski SC: Increased frequency of the ${\mathrm{C} 4 \mathrm{~A}^{\circ} \mathrm{O}}$ rare allele in Rheumatic heart Disease. Scandinavian J Rheumatol 24: 164-8, 1995. 